HStud 22 (2008) 1-2, 3-8

DOI: 10.15566/HStud.22.2008.1-2.1

\title{
HISTORIC MOMENTS OF HUNGARIAN FOLK DANCE: FROM THE GYÖNGYÖSBOKRÉTA TO THE DANCE HOUSE MOVEMENT
}

\author{
LÁSZLÓ DIÓSZEGI \\ Hungarian Dance Academy, Budapest \\ Hungary
}

\begin{abstract}
At the outset of the dance house movement, Sándor Csoóri, a prominent figure of contemporary Hungarian poetry, wrote that there were two outstanding events in the history of Hungarian folk dance. The first was when it got to the stage and the second when it got off the stage. This article expands on this poetically concise but pertinent thought, offers a short analyses of the defining periods of Hungarian folk dance, and gives some discussion of its main trends and representatives.
\end{abstract}

Keywords: Dance House, folk dance, staged dance, Hungarian, ethnography, folk music

Hungarian folk dance made its way to the stage relatively late, only in the first half of the 20th century, and it was then that it became widely known and acknowledged. This does not mean that isolated attempts to bring it into the limelight had not been made before, but what is certain is that earlier folk dance had not been known or appreciated by the Hungarian social elite.

Certainly, this statement does not go against the fact that at the time of our national culture's genesis, in the 18th and 19th centuries, during the eminent period of Hungary's history, the Reform Era, enlightened members of high society had already turned their interest to the folklore and thus also to the dances of the countryside. However, they were not terribly willing to view village life in its reality, but rather saw it in an imaginary and idealistic way. What they really wanted to show the public was not the alarming reality, but what they wanted to see in the art of the Hungarian people.

In fact, it was only in the 20th century that urban citizenry discovered the authentic life of the village. The "diszmagyar" raiment, (ceremonial attire) and the "palotás" (a dance of the nobility sensitive to national culture), thought to be traditional Hungarian costume and dance, turned out to have little to do with the genuine culture of the Hungarian village.

The performances of the Gyöngyösbokréta movement offered the first occasion for the public in Budapest to see authentic Hungarian folk dance. This move- 
ment had risen and evolved in the 1930s under the leadership of a journalist, Béla Paulini. It was launched with the specific aim of facilitating the identification of villages that had preserved their traditions, promoting the establishment of folk ensembles in these villages, and assisting the performance of their productions in theatrical settings. Each year on August 20th the ensembles of these "Bokrétás" villages were invited to present a short ten to twenty minute performance on the stage of the City Theatre, the largest theatre hall in Budapest, as part of the festive events marking St. Stephen's day.

The troupes presented the dances, music and folk traditions of their specific regions in an unaltered and almost intact manner. Undeniably, the productions were immensely inspiring and the dances were performed with a compelling vigor and dynamism barely conceivable for our generation. However, reportedly all the ensembles, whether from along the River Karád in the western part of the country or from the Gyimes region in eastern Transylvania (virtually 550 miles distant from each other) were accompanied by the same 25-member Gypsy music band conducted by Zsiga Rácz. This undoubtedly raises questions regarding the authenticity of the performances, but when it comes to evaluating the Gyöngyösbokréta movement what deserves emphasis is primarily the fact that it was in the framework of this movement that the culture, dances and traditions of the Hungarian village people made their way to the stage for the first time in history, thus bringing the art of the staged folk dance to life.

In addition to these unquestionably positive aspects, however, the movement nevertheless had negative effects. One of the main weaknesses of the Gyöngyösbokréta movement, a weakness the effects of which are still palpable today, was that it did not seek to present the reality of rural life, but rather an idealized "Sunday folklore," a schematized tradition, thus reinforcing the distorted image that urban people had already developed of the countryside. The Gyöngyösbokréta movement was swept away by the Second World War and the ensuing political changes, when Hungary, along with the other East European countries, fell militarily, economically and culturally under the control of the Soviet Union. Subsequently, the new artistic taste that marked Hungarian staged folk dance was not set by the nobility of the Reform Era traditionally educated in Vienna or by the revisionist-nationalist elite of Budapest still suffering from the shock of the Trianon treaty, but by Moscow, which was pursuing global power ambitions and thus bringing hundreds of small nations and vast areas, from Berlin to Vladivostok, under their yoke.

It was an advantage or perhaps a disadvantage for folk dance that the communist cultural policy also attached great importance to it. The Soviet cultural ideologists favored folk dance, as it did not involve the use of words (unlike the theater, perceived as a potential danger) and was inherently "happy" and "dumb." Folk 
dance acquired these latter features not least due to the inherited false genre-image that Gyöngyösbokréta also reinforced.

The only problem that folk art caused the Soviet authorities, who considered it to be the ideal form of art, was its national character. In order to overcome this, they developed a specifically sterilized and stylized type of folk dance, which was stripped of everything that was regarded as specific or national. The cultural ideologists did an excellent job, creating the Soviet people, the folk art of the Soviet Union, and an award bearing the name Folk Artist of the Soviet Union.

In the field of folk dance it was Igor Moiseyev, the talented, recently deceased artist, who managed to bring this "squaring of the circle" to completion in his art. The style marked by his name is devoid of defining stylistic features and displays a mixture of general forms of movement. And all this is done in a spectacular manner, with impressive choreography heavily enriched with acrobatic elements and performed on stage by an incredibly large number of dancers. An abundance of visually stunning elements, effects and show, with little if any authenticity, specificity or originality, is the essence of Moiseyevizm. It should be noted, however, that the phenomenon is not something unknown today in the world of folk dance. The only difference is that the choreographer is no longer Moiseyev, but Michael Flatley, and the dance is not the work of cultural ideologists from Moscow but by the financial magnates from New York. Impressive spatial forms, clichés often lost in a vague past, a reduced array of movements performed in a flamboyant manner in unison and by a large number of dancers, global music accompaniment and electronic instrumentation appealing to the modern ear, scenery provided with the aid of computers, and the inevitable smoke machine are the indispensable requisites of staged dance that falls under the category of entertainment industry.

As part of the Soviet block Hungary was clearly unable to withstand the cultural invasion of Moscow. Nevertheless, thanks to some prominent personalities who grew up under the influence of the Gyöngyösbokréta movement and who later became the most determining figures of both the science and art of Hungarian folk dance, Moiseyevizm could not gain absolute influence in Hungary. As a result, choreography of high artistic value based on the Gyöngyösbokréta movement, displaying the characteristic features of Hungarian folk dance, still managed to survive and maintain its presence alongside the Soviet style works in the folk dance of the 1950s.

Alongside the indisputable artistic accomplishments of the era, scholarly research of these years, which determined the future of Hungarian folk dance, should also be given due credit. The Folk Dance Department of the Institute for Musicology of the Hungarian Academy of Sciences launched a systematic, thoroughgoing and outstanding (even by European standards) research project under the leadership of György Martin, a Hungarian folklorist of international renown. Within the framework of the project researchers managed to record and process 
dance traditions of the villages in the Carpathians region in the final moment. The recorded material amounted to more than ten thousand meters of tape. Even today, after some 50 years, the collection still defines Hungarian folk dance, and in all probability numerous contemporary scholarly undertakings would be inconceivable without it.

When assessing the activities of István Molnár and Miklós Rábai, the two most outstanding choreographers of the time, we should not forget that the vast material collected by Martin and his team was not yet at their disposal. In fact they had only several documentary films of rather poor quality on which to base their studies. The silent, spring operated movie camera of the time was only suitable for recording short sequences. Moreover, as the spring grew more fatigued the recording became slower. Consequently it could only be replayed at a speed which made viewing almost impossible. Moreover, the prevailing cultural ideology dictated by Moscow, which did not welcome artistic trends dealing with or sympathizing with rural people and required that works display contentment, optimism and high spirits, made things even worse for Molnár and Rábai.

It should also be noted that prior to their efforts no pattern for folk dance choreography had been developed. They therefore had to cope with all the various problems of familiarizing themselves with the dance, arranging it for the stage, and dramatizing it. The roughness of their spatial forms and the simplicity of their motifs can be attributed to these unfavorable circumstances, as can the step combinations and the sequences that might seem of rather poor quality to the present day viewer. Nevertheless, their art, specifically that of István Molnár, was palpably different than that dictated by Moscow. Their activities not only lay the foundation for the Hungarian staged folk dance but created a new school of folk dance choreography. The majority of the authoritative choreographers of today, who started their careers in the 60s, regard themselves as Molnár's followers.

The 1960s marked the beginning of a new era in Hungarian folk dance. The creators and choreographers of the non-professional ensembles played an important role in exploring new creative avenues. The authoritarian regime, which was slowly easing its grip, focused its attention primarily on the professional ensembles and gave a certain freedom of movement to the non-professional troupes supported and supervised by the trade unions. It was among these troupes that choreographers Katalin Györgyfalvai, Károly Szigeti, Antal Kricskovics, Ferenc Novák and Sándor Tímár, all of whom acquired their knowledge of dance as professional dancers, carried out their activities from the 1960s on. The new generations were looking for new modes of expression and regarded dance as a means of self expression. They were determined to break with the Moiseyevist conception of folk dance. For this reason, instead of radiating the obligatory cheerful, content and carefree spirit or staging pseudo-conflicts, their choreographies reflected the problems of everyday life and were of a dramatic, somber tonality befitting the 
prevailing mood of society. They often worked together closely with representatives of related arts, such as writers, poets and theater or film directors. Thanks to their undertakings Hungarian folk dance managed to break free from the political quarantine of the 1950s and grow up to become an art form in its own right.

The broadened artistic horizons of the 1970s and the findings of studies conducted in the field of folk music and folk dance brought about new developments in Hungarian folk dance. The role of tradition was reinterpreted and became the focus of interest. In the field of folk dance this led to the realization that tradition can generate artistic experience in its own right and at the same time exert influence with an overwhelming force to address the exigencies of modern times. An accomplishment of the 1970s that was perhaps even more remarkable was that folk dance ceased to be an enviable privilege of a few select artists, a staged attraction or an estranged work of art. Rather it was returned to its original context and regained its initial function. Within the folk dance movement, which started to unfold during these years, folk dance again became part of the lives of young people as a source of entertainment and a means of meeting one another.

Obviously young village people in rural dance houses or wedding celebrations entertained themselves not with choreographed dances but rather with improvised dance. It was, however, no easy task to learn an improvised dance, as the code language of the dance had to be deciphered first, its structure and grammar understood, and its words, which is to say the motifs of the dance, mastered. It is György Martin and Sándor Tímár who can be credited with this revolutionary discovery. After decoding the native language of the dance, Tímár developed a method by which he could effectively teach dances of various styles. Their discovery caused a global sensation in the 1970s and 1980s. It is no wonder that the master and his pupils were invited to teach dances of the Carpathian Basin and methods of improvised dancing in locales from the USA to Japan. It should also be noted that in the meantime the dance house movement had consolidated in Hungary. It is partly as a result of this that even today over ten-thousand students are acquiring the skill of improvised dancing through the art school network.

The dance house movement and improvised dance also led to major changes in the art of staged folk dance. The habit of staging dance tradition without alterations came to be customary or rather virtually exclusive practice. This required a high degree of knowledge of dance on the part of the dancers and varied spatial formation on the part of the choreographer. The colorful character of the performances, their expressiveness, the dramaturgy, and the use of theatrical means, however, were essentially ignored.

The folk dance of the 1970s and 1980s was marked by the discovery of the rich regional dance traditions of the Carpathian Basin. Each year the groups, particularly the Bartók Ensemble led by Sándor Tímár, came out with new choreographies composed of dance styles never seen before. The need to create some- 
thing new and the excitement felt over the discovery of new directions pushed the desire for artistic renewal into the background.

With the exhaustion of the stock of new dance styles, however, it became clear that stage art cannot do without original artistic solutions, as forms applied with great success in the beginning soon grow conventional. Tímár's choreography comprises real dance sequences performed in unison usually by a great number of dancers and in attractively constructed spatial forms. This was apparent at the professional company of the Hungarian State Folk Ensemble.

We should acknowledge, however, that Tímár composed his productions with such masterly skill and sense of proportion that these shortcomings were rarely apparent.

In the 1990s the stage for Hungarian folk dance was the scene of the appearance of new productions. These compositions placed emphasis on the individual, while the dance sequences, the music and the costumes were based on very thorough and scholarly research. Tímár's spatial-form choreography was replaced by a non-composed type of choreography that placed the dancer and the dance in the spotlight. Its representatives drew inspiration often and with great relish from folk traditions.

At the same time, there were other works coming to the stage, which after a 20 -year hiatus carried on the traditions of the 1960s, pursuing new means of expression and demonstrating individual artistic approaches. However, only time will tell whether these works will be enduring, just as only time will tell whether it will be possible to bring a new Hungarian dance style to life similar to folk music, a style that will not merely be a masterly imitation of folk dance, but rather a creative and artistic rearrangement of it in such a manner that it can be both modern and deeply rooted in the present day and still retain the virtues, compactness, balance, plainness and simplicity of folk art. 